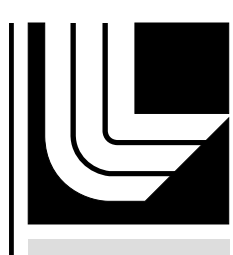

LAW RENCE LIVERMORE N A TION A L LABORATORY

\title{
Laser-matter Interaction with Submerged Samples
}

R. Mariella, A. Rubenchik, M. Norton, G.

Donohue, K. Roberts

April 12, 2010 
This document was prepared as an account of work sponsored by an agency of the United States government. Neither the United States government nor Lawrence Livermore National Security, LLC, nor any of their employees makes any warranty, expressed or implied, or assumes any legal liability or responsibility for the accuracy, completeness, or usefulness of any information, apparatus, product, or process disclosed, or represents that its use would not infringe privately owned rights. Reference herein to any specific commercial product, process, or service by trade name, trademark, manufacturer, or otherwise does not necessarily constitute or imply its endorsement, recommendation, or favoring by the United States government or Lawrence Livermore National Security, LLC. The views and opinions of authors expressed herein do not necessarily state or reflect those of the United States government or Lawrence Livermore National Security, LLC, and shall not be used for advertising or product endorsement purposes.

This work performed under the auspices of the U.S. Department of Energy by Lawrence Livermore National Laboratory under Contract DE-AC52-07NA27344. 
Laser-matter Interaction with Submerged Samples

Tracking Code 09-FS-002 LDRD Feasibility Project, \$125K

\author{
R. Mariella Jr., A. Rubenchik, M. Norton, G. Donohue, K. Roberts
}

\begin{abstract}
$\underline{\text { Abstract }}$
With the long-term goal in mind of investigating if one could possibly design a "universal solid-sample comminution technique" for debris and rubble, we have studied pulsed-laser ablation of solid samples that were contained within a surrounding fluid. Using pulses with fluences between $2 \mathrm{~J}$ and $0.3 \mathrm{~J}$, wavelengths of 351 and $527 \mathrm{~nm}$, and samples of rock, concrete, and red brick, each submerged in water, we have observed conditions in which $\mu \mathrm{m}$-scale particles can be preferentially generated in a controlled manner, during the laser ablation process. Others have studied laser peening of metals ${ }^{1-6}$, where their attention has been to the substrate. Our study uses non-metallic substrates and analyzes the particles that are ablated from the process. The immediate impact of our investigation is that laser-comminution portion of a new systems concept for chemical analysis has been verified as feasible.
\end{abstract}

\title{
Introduction
}

When a laser pulse with sufficiently high energy density strikes the interface between water and a hard material, it forms a plasma layer. The resultant shock waves ${ }^{7,8}$ propagate in both directions from the plasma ${ }^{9,10}$, possibly ablating material [e.g., see Fig 1 from the work of Grigoropoulos and coworkers $\left.{ }^{11}\right]$. The water confines the expanding plasma, increasing the pressure and temperature and the plasma lifetime ${ }^{9,12}$. Much-higher-pressure pulses are observed with submerged samples than with samples in air $^{9,13,14}$. As the plasma/vapor of ablated material cools, solid particles nucleate and grow. Increased pressure and temperature has been observed to accelerate dissolution of oxides ${ }^{15,16}$. Dissolution of ceramics in $\mathrm{KOH}$, enhanced by laser beam ${ }^{17}$. Laser pulses produce nanoparticles, even with submerged samples ${ }^{18,19}$. In one study of the nanoparticles that were generated with fs-laser pulses, a lower ablation rate was observed for samples in water than for samples in gas ${ }^{20}$. Studies of nanoparticles from fs-laser pulses have also been performed with samples of hydroxyapatite ${ }^{21}$ and II-VI semiconductors ${ }^{22}$. Under some circumstances, the presence of water can increase the amount of ablated material ${ }^{23,24}$. When the sample is a metal, the shock wave that propagates into it can improve some of its properties; this is the basis of "laser peening.", $, 9,14$ Above a wavelength-dependent threshold, a parasitic plasma may form, in which the laser radiation can be almost completely absorbed in the plasma ${ }^{25}$, limiting the laser power that can reach the surface ${ }^{26}$.

Our first step in modeling of particle formation is an estimate of the thickness of the ablated material.

\section{Basic model.}

The pulsed laser radiation, that is absorbed at the water-material interface, boils and ionizes the material into a thin, expanding plasma zone, which can be characterized as "warm, dense plasma." The rapid expansion produces shock waves that propagate both into the water and into the solid material. For our application, this zone is very thin and can be treated for the rest of the material as a boundary condition for the material code.

One way to simulate the laser matter interaction is to use the modeling code, LASNEX ${ }^{27}$. However, LASNEX is optimized and benchmarked for high-intensity light interaction [electron and ion temperatures measured in $\mathrm{keV}$ ] with an expanding, low-density plasma ${ }^{27-29}$, and its applicability to a high- $Z$, high-density (near-solid-state density) plasma [estimate that $\mathrm{T} \approx 1 \mathrm{eV}$ ] is uncertain. In this situation it is attractive to use instead a simple, semi-empirical model ${ }^{30}$, an extension of our previous work ${ }^{25}$, that has been benchmarked in laser peening experiments.

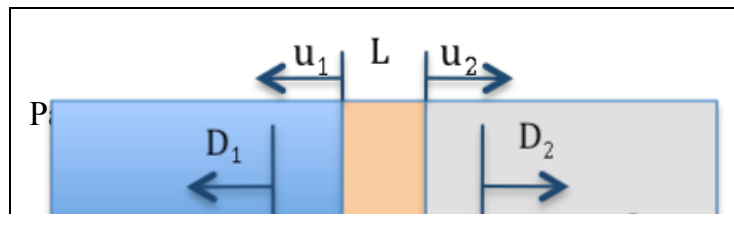


Fig.1 Laser matter interaction in confined geometry. $\mathrm{u}_{1}$ and $\mathrm{u}_{2}$ are the velocities of the expanding plasma of thickness $\mathrm{L}$, and $\mathrm{D}_{1}$ and $\mathrm{D}_{2}$ are the shock velocities.
Fig.2 Pressure produced by the direct ablation-red line, ablation in confined geometry -water-Al interface-green line, glass-Al interface-blue line

The geometry of the problem is presented on the Fig.1. The laser energy is deposited at the interface of the solid material with the transparent one [subscripts 1 and 2, respectively, in Fig 1 and in the following equations]. The deposited energy produced the expanding plasma layer with thickness $\mathrm{L}$ and two shocks propagating out of interface. Plasma confinement by the transparent material increases the pressure on the metal boundary.

The plasma boundary motion is a result of the material motion behind the shocks. We follow the notation of Fabbro, et $\mathrm{al}^{4}$. For plasma thickness $\mathrm{L}$ we have

$$
\frac{d L}{d t}=u_{1}+u_{2}=\frac{2 P}{Z}
$$

where we used the relation $P=\rho_{i} u_{i} D_{i}$ and assumed that for the weak shocks that the shock speed $\mathrm{D}$ coincides with local sound speed. Here $\mathrm{Z}$ is the effective interface impedance

$$
\frac{2}{Z}=\frac{1}{Z_{1}}+\frac{1}{Z_{2}}
$$

where

$$
Z_{i}=\rho c_{s i}
$$

and $\mathrm{c}_{\mathrm{si}}=$ sound speed in material "i".

The absorbed laser energy is used to increase plasma energy in the layer and as work to expand it against the confining fluid. The energy deposited by laser $I d t$ is used to increase the plasma internal energy $\mathrm{E}_{\mathrm{i}}$ by $d\left(E_{i} L\right)$ and as work of pressure force $P d L$. Then we have

$$
I(t)=P(t) \frac{d L}{d t}+\frac{d\left(E_{i} L\right)}{d t}
$$

Now, we assume that there is a constant division of the internal energy, where $\alpha$ represents the thermal energy $\mathrm{E}_{\mathrm{T}}$ and the fraction (1- $\left.\alpha\right)$ represent the energy of ionization. This assumption is equivalent to the assumption of effective adiabatic index [no radiative energy loss], as is used in discharge physics ${ }^{4}$.

$$
\gamma-1=\frac{2}{3} \alpha
$$

From early experiments ${ }^{4,5,12,26,31} \alpha \sim 0.1$ to 0.2 and data derived from SESAME equation of state $^{32}$ for $\mathrm{Al}$ gave values of $\alpha$ in the range 0.1-0.3. Later studies using better shock diagnostics ${ }^{33}$ recommend $\alpha=0.25$.

For a plasma, treated as ideal gas, the pressure is related to the internal energy

$$
P=\frac{2}{3} E_{T}=\frac{2}{3} \alpha E_{i}
$$

and finally we have

$$
I(t)=P(t) \frac{d L}{d t}+\frac{3}{2 \alpha} \frac{d[P(t) L(t)]}{d t}
$$


The system of equations (1.1),(1.2) provides the closed description of the laser plasma interaction in peening experiments ${ }^{10,14}$.

\section{Scalings}

The equations (1.1),(1.2) have an analytical solution for a flat top laser pulse with intensity I. The pressure is constant during the pulse and given by expression ${ }^{12}$

$$
P(\text { kbars })=0.1 I^{0.5}\left(G w t / \mathrm{cm}^{2}\right)\left(\frac{\alpha}{2 \alpha+3}\right)^{1 / 2} Z^{1 / 2}\left(\mathrm{~g} / \mathrm{cm}^{2} \mathrm{~s}\right)
$$

The total plasma length, $\mathrm{L}$, increases linearly in time and at the end of the pulse is

$$
L(\mu m)=\frac{2 * 10^{4} P(\text { kbars }) \tau(n s)}{Z\left(\mathrm{~g} / \mathrm{cm}^{2} \mathrm{sec}\right)}
$$

The thickness of ablated material 1 is given by the

$$
l=L \frac{Z_{2}}{Z_{2}+Z_{1}}
$$

After pulse termination, the plasma produced by the laser cools down adiabatically, keeping the pressure high for some time. As a result, the pressure pulse is typically longer than the laser pulse duration 2-3 times ${ }^{13,14}$.

In Fig.2, we presented the calculation of pressure for direct ablation and for the Al-glass and Al-water interface irradiated by a $10-\mathrm{nsec}$ pulse of a $1-\mu \mathrm{m}$ laser. We used $\alpha=0.2$. Decreasing $\alpha$ to 0.1 changes the pressure less then $30 \%$. For the ablation pressure produced by the laser light without confinement, we used the expression ${ }^{12}$

$$
P(k b a r s)=3.9 I^{0.7}\left(G w t / \mathrm{cm}^{2}\right) \lambda^{-0.3}(\mu m) \tau^{-0.15}(n \mathrm{sec})
$$

This expression is not sensitive to the target material, at least for not very heavy metals. We see that confinement geometry greatly increases the generated pressure.

For laser pulse with one-scale temporal profile $\mathrm{e}^{34,35}$ of duration $\tau$, from dimensional analysis of system (1.2),(1.1), we can get

$$
\begin{aligned}
& P=Z^{1 / 2} I^{1 / 2} f\left(\alpha, \frac{t}{\tau}\right) \\
& L=\frac{I^{1 / 2}}{Z^{1 / 2}} \tau g\left(\alpha, \frac{t}{\tau}\right)
\end{aligned}
$$

As we mentioned above the value of $\alpha$ is small and we can disregard the PdV work term in (1.2). From comparison with (2.1) we see that for $\alpha=0.1$, the accuracy of this approximation is better then $10 \%$. In this case the $\alpha$ scaling becomes explicit 


$$
\begin{aligned}
& P=Z^{1 / 2} I^{1 / 2} \alpha^{1 / 2} f\left(\frac{t}{\tau}\right) \\
& L=\frac{I^{1 / 2} \alpha^{1 / 2}}{Z^{1 / 2}} \tau g\left(\frac{t}{\tau}\right)
\end{aligned}
$$

An analytical solution can, nonetheless, be derived, including the PdV work. The pressure on the interface can be determined from the equations.

$$
I(t)=\frac{3}{2 \alpha} \frac{d[P(t) L(t)]}{d t} ; \frac{d L}{d t}=\frac{2 P}{Z}
$$

The analytical solution of (2.5) for pressure is given by the expression

$$
P(t)=\sqrt{\frac{\alpha Z}{6}} \frac{\int_{-\infty}^{t} I(x) d x}{\left(\int_{-\infty}^{t}(t-x) I(x) d x\right)^{1 / 2}}
$$

For one-scale temporal profile of laser pulse

$$
I(t)=I f\left(\frac{t}{\tau}\right)
$$

the pressure is

$$
P=Z^{1 / 2} I^{1 / 2} \alpha^{1 / 2} g(s) ; s=\frac{t}{\tau}
$$

where the structural function $\mathrm{g}$

$$
g=\frac{\int_{-\infty}^{s} f(x) d x}{\left(6 \int_{-\infty}^{s}(s-x) f(x) d x\right)^{1 / 2}}
$$

For flat top pulse $g=1 / \sqrt{3}$ and the pressure is

$$
P(\text { kbars })=0.1 I^{0.5}\left(G w t / \mathrm{cm}^{2}\right)\left(\frac{\alpha}{3}\right)^{1 / 2} Z^{1 / 2}\left(g / \mathrm{cm}^{2} s\right)
$$

For plasma length we have

$$
L=\left(\frac{8 \alpha I}{3 Z}\right)^{1 / 2} \tau p(s) ; s=\frac{t}{\tau}
$$

with the structural function $p$ 


$$
p(s)=\left[\int_{-\infty}(s-x) f(x) d x\right]^{1 / 2}
$$

The above expressions (2.7-2.9) give the pressure plasma size dependence of all laser and material parameters for fixed pulse shape. For fixed pulse shape $g(s)$ and $p(s)$ can be tabulated and then, can be used for the pressure pulse evaluation for the different materials and laser parameters. After the pulse termination, plasma expands adiabatically, $\mathrm{P} \sim 1 / \mathrm{L}^{\gamma} \sim 1 \sqrt{\mathrm{t}}$. The pressure behavior for the Gaussian laser pulse is presented on the Fig.3. The red line presents the laser pulse, green-the pressure on interface.

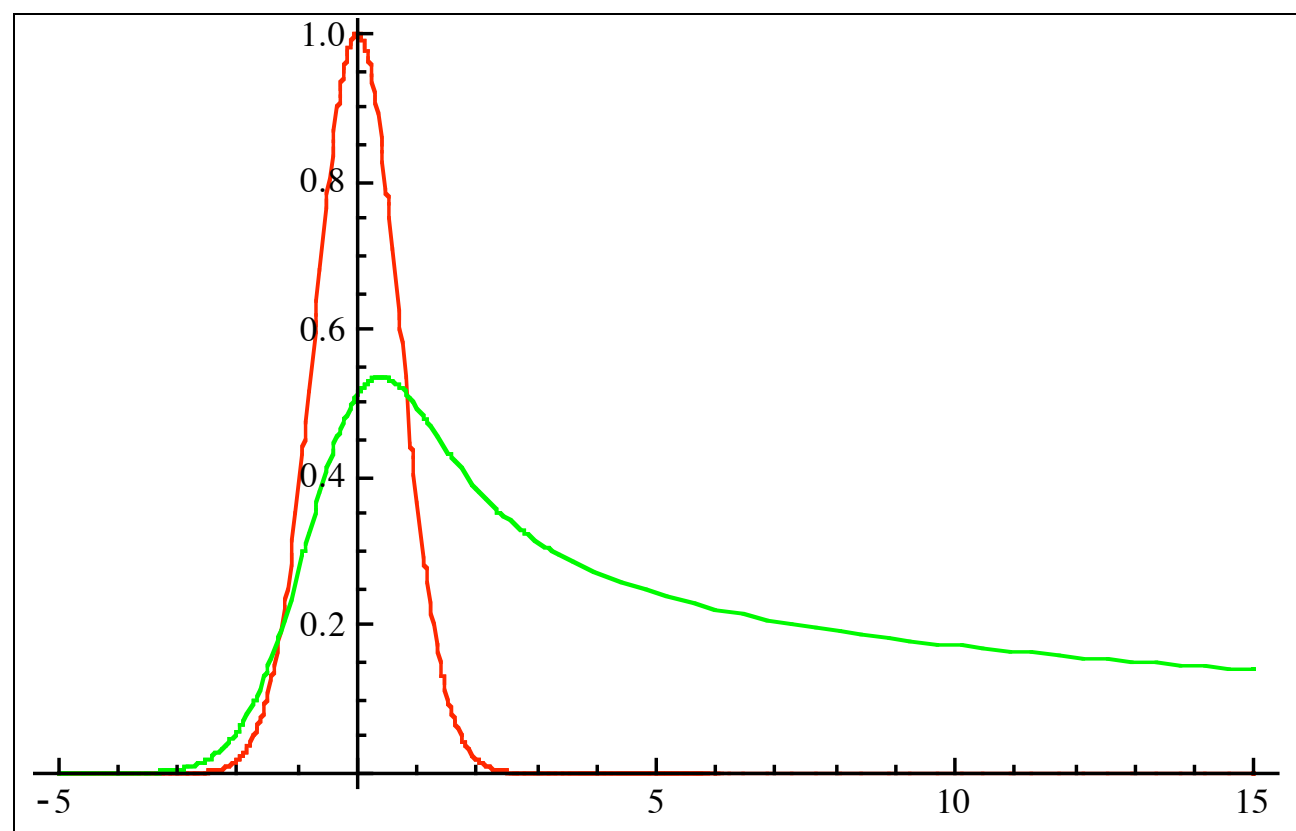

Fig.3 Laser pulse-red line and pressure pulse-green line as function of $\mathrm{t} / \tau$

The important parameter for the peening process is the total impulse momentum transferred to the material $\mathrm{M}$. The thickness of plastically deformed layer is proportional to $\mathrm{M}^{3,14}$.

$$
M=\int_{-\infty}^{\infty} P d t \approx Z^{1 / 2} I^{1 / 2} \alpha^{1 / 2} \tau B \approx Z^{1 / 2} F^{1 / 2} \alpha^{1 / 2} \tau^{1 / 2} B ; B=\int_{-\infty}^{\infty} g(x) d x
$$

As we mentioned above the pressure drop is slow and B diverges. Really, we must limit the integration in (1.7) by the moment the plasma recombination starts or the liner moves out. Typically, the time is about $0.1 \mu \mathrm{sec}$ and is insensitive to the exact value of cut off. For a example $\mathrm{B}(10)=3.4, \mathrm{~B}(15)=4.2$. For the numerical estimates below we will use $\mathrm{B}=4$.

The formal expression for plasma length diverges at long time. Due to the same reason we must use $s \sim 3$ to get the maximal plasma size and the depth of the ablated material

\section{Applicability and numerical estimates.}

The above model is applicable when the laser intensity is high enough to produce the ionization. According to measured data ${ }^{14}$ the intensity must be above $0.5 \mathrm{GW} / \mathrm{cm}^{2}$, but the value is not exact. One needs to apply (1.2). The maximal intensity must not be very high, in order to 
prevent the water breakdown. Fabbro et. al. ${ }^{4,5,31}$, Indicates that for $1-\mu \mathrm{m}$ light the intensity must be not higher than $10 \mathrm{GW} / \mathrm{cm}^{2}$.

The thickness of ablated material 1 is related to the plasma size $\mathrm{L}$ by the relation

$$
l=\frac{Z_{2}}{Z_{1}+Z_{2}} L \propto \frac{Z_{2}}{Z_{1}+Z_{2}} \tau \sqrt{\frac{I \alpha}{Z}}
$$

If we use pulses of fixed intensity and duration, we must maximize the amount of the ablated material $\mathrm{V}=\mathrm{S}$ times 1 , where $\mathrm{S}$ is the spot size. From above we have

$$
V=\frac{Z_{2}}{Z_{1}+Z_{2}} \sqrt{\frac{E S \tau \alpha}{Z}}
$$

We see that for maximal volume of evaporated material we must use the biggest spot size compatible with plasma formation. This means that we use an intensity of about $1-2 \mathrm{GW} / \mathrm{cm}^{2}$.

The formula (3.2) also gives a possibility to estimate a comparative rate of different material processing using their impedance values.

In Table 1 we present the impedance data for few materials. It must be mentioned that the sound speed and density changes with the temperature and the pressure. We disregard it for calculation of the pressure pulse, but the error typically falls within the accuracy of the model. Instead of LASNEX type plasma codes, an alternate modeling description ${ }^{4,12,26,31,36,37}$ of the experiment works well, based on the above model.

\begin{tabular}{|l|l|l|l|}
\hline Material & $\rho$ & $\mathrm{s}(\mathrm{km} / \mathrm{sec})$ & $\mathrm{Z}^{*} 10^{-6}\left(\mathrm{~g} / \mathrm{cm}^{2} \mathrm{sec}\right)$ \\
\hline Steel & 7.85 & 5.85 & 4.59 \\
\hline Concrete & 2.6 & 3.1 & 0.8 \\
\hline Water & 1 & 1.65 & 0.165 \\
\hline Ti & 4.52 & 5.1 & 2.3 \\
\hline Fused silica & 2.2 & 4.6 & 1.3 \\
\hline Al & 2.7 & 5.4 & 1.5 \\
\hline
\end{tabular}

Consider the water-Al interface. For $Z$ we have $\sim 0.3$ and for $\alpha=0.25$ and intensity $4 \mathrm{GW} / \mathrm{cm}^{2}$ we have a peak pressure $\sim 29 \mathrm{kbar}$. Plasma length at the end of $10 \mathrm{nsec}$ pulse is about $19 \mu \mathrm{m}$. For the thickness of Al turns to plasma from (3.1) we have about $1.9 \mu \mathrm{m}$.

This result is consistent with the size of particles $\sim 1 \mu \mathrm{m}$ we found in water samples taken after laser peening processing in Metal Improvement Corp.

For concrete, for the same intensity we will ablate 1.8 times more material, about $3.4 \mu \mathrm{m}$. Also, the pressure will be a little bit lower $\mathrm{P} \sim 27.8 \mathrm{kbar}$.

\section{Discussion}

There are few additional effects we do not taking into account which can additionally breaks the material and increase the processing rate.

1. After the pulse termination plasma, then vapor expands isolating the material surface from the water. The front of the expansion is Rayleigh-Taylor unstable and jets of water reches the hot material surface producing the thermal shock and cracking the material. This effect is not important for metals but for concrete may be it can take place.

2. The air bubbles produced after plasma-vapor zone collapsed, cavitates, produce the local shock and jet streams wich can erode the material.Again this effect is not important for metals. 


\section{LLNL-TR-XYXYXY}

3. The shock produced by the laser pulse can crash the material and increase the errosion.

4. Finally, above we assume the surface absorption. In concrete the laser light can penetrates deeper then couple of microns increaseing the errosion rate. Both effects are not important for the metals.

The above discussion was independent of wavelength. The reason is that we assumed that on the front of the pulse we creates the plasma which absorbed all laser radiation. It is true for high enough laser intensity -about $0.5-1 \mathrm{GW} / \mathrm{cm}^{2}$ for $1 \mu \mathrm{m}$ light. For green light the threshold intensity can be lower and we can operates at lower intensities. Also, the green light has 100 times longer absorption length in water than $1-\mu \mathrm{m}$ light, and it can be attractive to use it from the operational point of view

\section{Number of pulses to break the sample into nanoparticles}

To estimate the number of pulses we use the formula for amount of evaporated materials obtained within the peening model ${ }^{10}$.

The thickness of ablated material $L$ is related to the plasma size $L$ by eqn 3.1. If we use the pulses of fixed intensity and pulse duration, we must maximize the amount of the ablated material $\mathrm{V}=\mathrm{S}$ times $L$, where $\mathrm{S}$ is the spot size. From eqn 3.2, we see that for maximal volume of evaporated material we must use the biggest spot size compatible with plasma formation. Probably, this means that we must use the intensity about $1-2 \mathrm{GW} / \mathrm{cm}^{2}$.

$$
L(\mu m)=\frac{2 X 10^{4} P(k b a r s) \tau(n s)}{Z_{1}\left(g / \mathrm{cm}^{2} \mathrm{sec}\right)}
$$

Applying eqns 2.1 and 2.2 for a rectangular pulse with: duration $\tau$, water $Z=0.165 \times 10^{6}$ $\left(\mathrm{g} / \mathrm{cm}^{2} \mathrm{sec}\right)$, concrete $\mathrm{Z}=0.8$ in the same units, $\alpha=0.25$, and intensity $2 \mathrm{GW} / \mathrm{cm}^{2}$ we get the pressure $\mathrm{P}=19.8 \mathrm{kbar}$. Assuming a pressure-pulse duration about 3 laser-pulse durations ${ }^{13,14}$, where the pulse duration is $15 \mathrm{~ns}$ for SLAB laser, we get for the thickness of pulverized concrete $L \sim 11 \mu \mathrm{m}$. For pulse energy $15 \mathrm{~J}$ and pulse duration of $15 \mathrm{~ns}$ the laser spot with intensity of 2 $\mathrm{GW} / \mathrm{cm}^{2}$ will have an area of $0.5 \mathrm{~cm}$. So, the volume removed per one shot is about $\sim 5^{*} 10^{-4} \mathrm{~cm}^{3}$. The density of concrete is $\sim 2.6 \mathrm{~g} / \mathrm{cm}^{3}$, and the volume of $1 \mathrm{~g}$ is about $0.4 \mathrm{~cm}^{3}$. To pulverize all the volume one needs $\sim 800$ shots and for a repetition rate of $4 \mathrm{~Hz}$ it will take about $200 \mathrm{sec}$, [3.3 minutes].

Let us mention that really material can be destroyed faster. The pressure pulse is reflected from the rear surface as a tensile stress with reflectivity

$$
R=\left(\frac{Z_{1}-Z_{2}}{Z_{1}+Z_{2}}\right)^{2}=0.43
$$

The tensile pressure wave with pressure about $10 \mathrm{kbars}$ can spall out the pieces with size $\mathrm{a} \sim \mathrm{s} \tau$. For pulse duration $\sim 15 \mathrm{~ns}$ and sound speed in concrete $\sim 3 \mathrm{~km} / \mathrm{sec}$ the particles with size a $\sim 50$ $\mu \mathrm{m}$ will be produced.

5. Motion of particles in water.

The small particle in the water sediments under the influence of gravity, but Stokes drag force ${ }^{38,39}$ balances this. For a particle with radius "a" in water with constant velocity "v," the Stokes drag force compensates gravity force

$$
\left(\rho-\rho_{w}\right) g \frac{4}{3} \pi a^{3}=6 v \pi \eta a
$$


The velocity is proportional to the square of particle size

$$
v=\frac{2\left(\rho-\rho_{w}\right) g a^{2}}{9 \eta}
$$

Consider the concrete particle with density $\sim 2.6 \mathrm{~g} / \mathrm{cm}^{3}$ in water with viscosity $\eta=0.01 \mathrm{~g} / \mathrm{s}$-cm; we find $\mathrm{v}=3.5 \times 10^{-4} \mathrm{a}^{2} \mathrm{~cm} / \mathrm{sec}$, where radius a is in $\mu \mathrm{m}$. One can see that for particles with the size $<$ $1 \mu \mathrm{m}$, the gravity-driven velocity is not important. For particles produced due to the spallation with the size $\mathrm{a} \sim 50 \mu \mathrm{m}$, the steady-state falling velocity $\mathrm{v} \sim 0.9 \mathrm{~cm} / \mathrm{sec}$ and between the pulses they can fall down from the laser spot. [At low laser-pulse repetition rates, agitation/stirring of the suspension will be necessary, if one desires to comminute the spalled particles to sub- $\mu \mathrm{m}$ scale] Disregarding gravity, the velocity evolution is described by the equation

$$
\rho \frac{4}{3} \pi a^{3} \frac{d v}{d t}=(u-v) 6 \pi \eta a
$$

let $\mathrm{a}=$ radius of sphere in water, $\eta$ is the viscosity

$$
\begin{aligned}
& \mathrm{u}_{\infty}=2 \mathrm{~g} * \Delta \rho * \mathrm{a}^{2} / 9 \eta \\
& \text { and }^{39} \\
& \mathrm{t}=\ln \left[\left(\mathrm{u}_{\infty} /\left(\mathrm{u}_{\infty}-\mathrm{u}\right)\right]\right.
\end{aligned}
$$

or

$u=u_{\infty}\left(1-e^{-\left(t /\left(2 \rho a^{2} / 9 \eta\right)\right)}\right)$

Which shows the characteristic time $\tau$ for the velocity onset is

$$
\tau=\frac{2 \rho a^{2}}{9 \eta}
$$

$\operatorname{Re} \approx 3 \times 10^{-3}$ for a $10-\mu \mathrm{m}$ particle, so flow is laminar. For viscosity used above $\tau=0.58 * 10^{-2} a^{2}$ sec. where a is measured in hundreds of $\mu \mathrm{m}$.

One can see that for the particles with $\mathrm{a} \approx 10 \mu \mathrm{m}, \tau \approx 60 \mu \mathrm{s}$ and one can consider the particles moving with stationary falling velocity. To prevent the concentration of the particles on the bottom of the volume with the sample we must have water flow with the velocity $1 \mathrm{~cm} / \mathrm{sec}$. It can be the convective flow or slow rotation of the volume with the sample. 


\section{Experimental}

In previous work at LLNL, a slab laser was developed to study laser peening of metals ${ }^{40}$. For the experiments, reported here, we used 351-nm [3- $\omega]$ pulses of $\approx 15$-ns duration from this laser, with samples of rock [quartzite ${ }^{41}$, see Fig. 5] or concrete [see Fig. 10] as targets that we submerged within $700 \mathrm{ml}$ of de-ionized water.Figure 1 is a photo of our experimental setup.

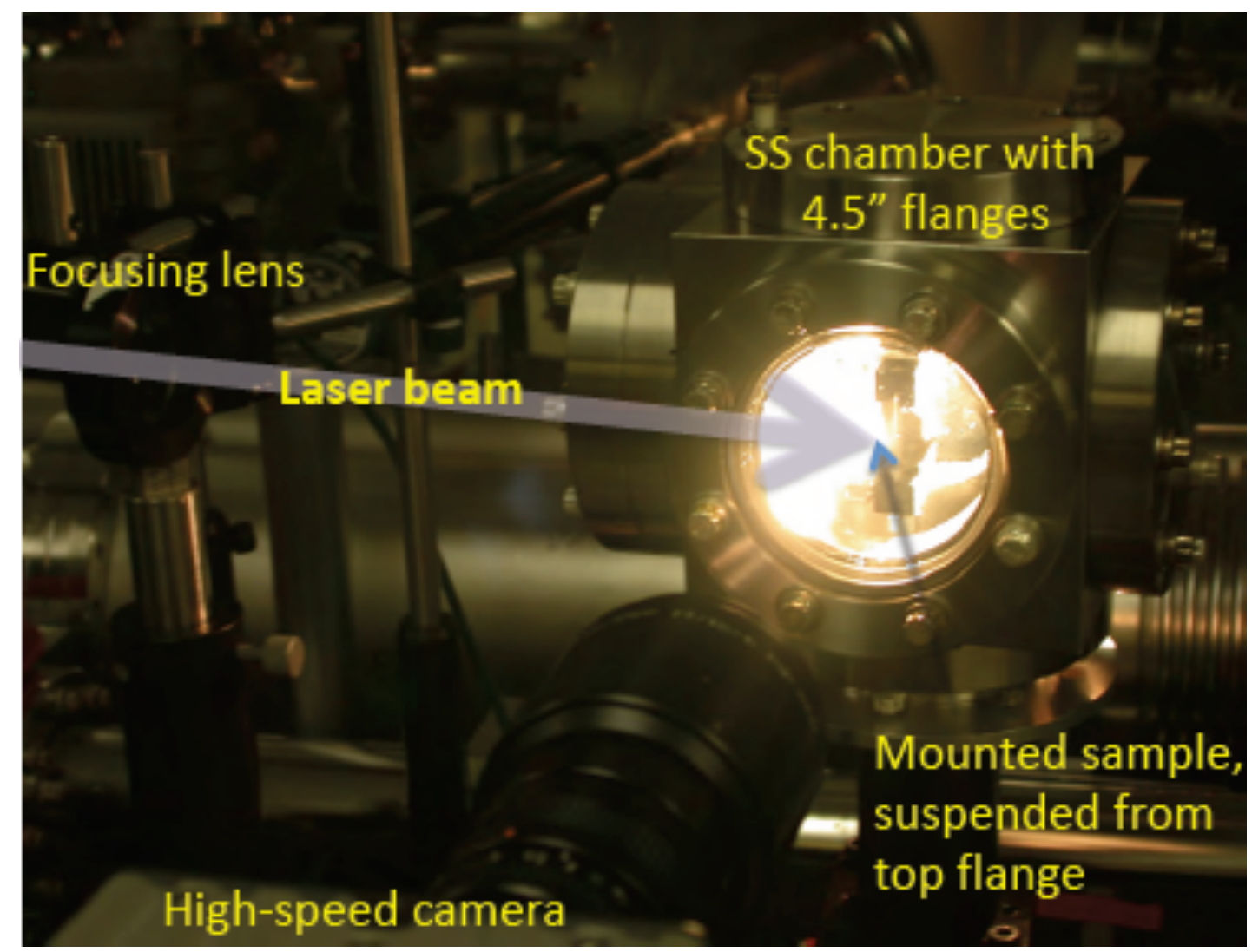

Figure 4. Photo of experimental setup.

We performed two different series of experiments using light at $351 \mathrm{~nm}$. In the first series, with a broken sample of quartzite, we used a focusing lens so that the approximately-square beam area was roughly $0.1 \mathrm{~cm}^{2}$ on the sample surface. With $0.7 \mathrm{~J}$ in a $15-\mathrm{ns}$ pulse, this meant a power of 7 $\mathrm{J} / \mathrm{cm}^{2} / 1.5 \times 10^{-8} \mathrm{~s} \approx 0.47 \mathrm{GW} / \mathrm{cm}^{2}$. This power proved to be too high for controlled ablation, since the expanding plasma generated a bubble in the water which collapsed, possibly in a water jet like a micro shape charge, and the impact of this liquid water on the superheated surface caused ejection of particles up to $100 \mu \mathrm{m}$ in diameter [see Fig. 7], in addition to the fine particles that were produced during the plasma expansion. We reduced the energy to $0.35 \mathrm{~J}$, still using the focusing lens, and continued to observe the occasional ejection of $\approx 100-\mu \mathrm{m}$ particles.

In our next series of ablation studies, we removed the lens and used the unfocused laser beam, measured at $2.5 \mathrm{~cm}^{2}$, with $1 \mathrm{~J} /$ pulse, or roughly $\mathrm{I}=0.027 \mathrm{GW} / \mathrm{cm}^{2}$. With this power and $351-\mathrm{nm}$ wavelength, we observed the formation of "clouds" of microparticles, which remained suspended for 30 minutes or longer. The lack of sedimentation confirmed the $\mu \mathrm{m}$ and nm scale of the particles that were formed.

In every experiment, we surrounded all sides of any sample, except for its front, with a 300mesh, stainless-steel screen from The Western Group, 1 Blue Sky Ct., Sacramento, CA 95828. This was done, because we wanted to capture any particle that might spall from the back or sides of a sample, due to the effects of a shock wave striking one of these surfaces. At the power levels that we employed for our experiment, we found no evidence of such spall. 


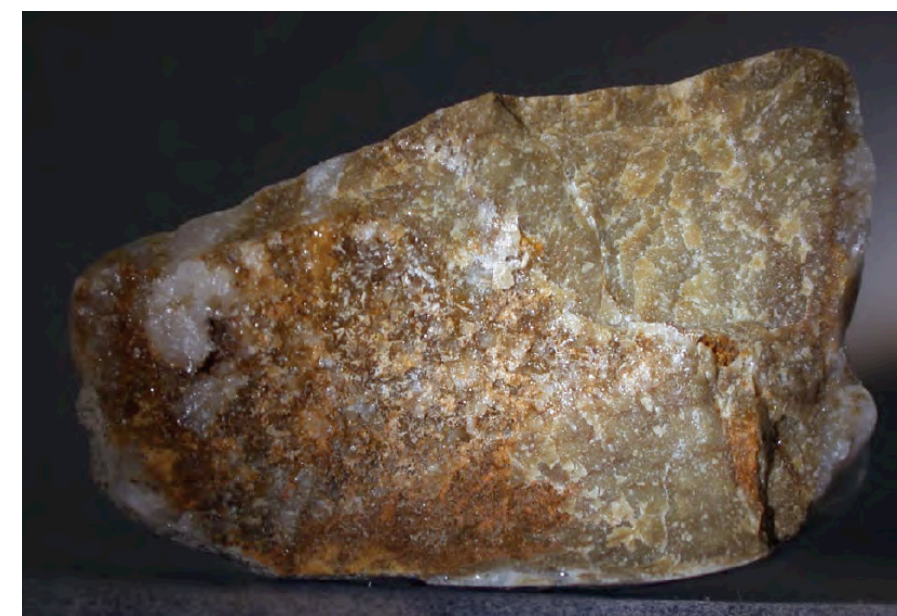

Figure 5. pre-shot photo of sample \#1

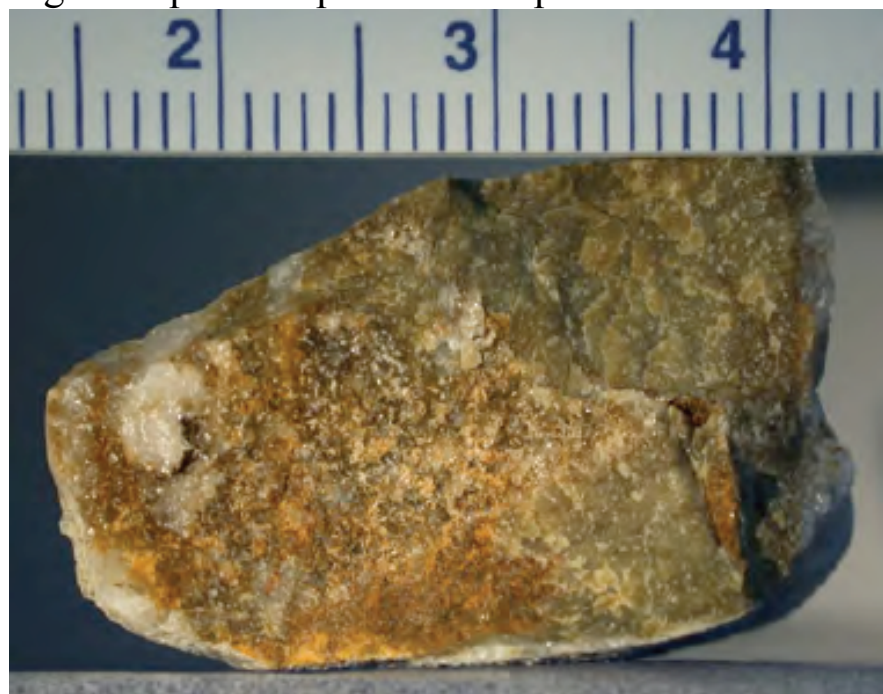

Figure 6. pre-shot photo of sample\#1, with cm scale

Rock target, $0.7 \mathrm{~J}$ pulse, focused into a 3-mm diameter spot on submerged Rock's surface - a violent process. Some microparticles formed via plasma ablation, but bubble collapse/cavitation/water jet also ripped larger chunks from the surface

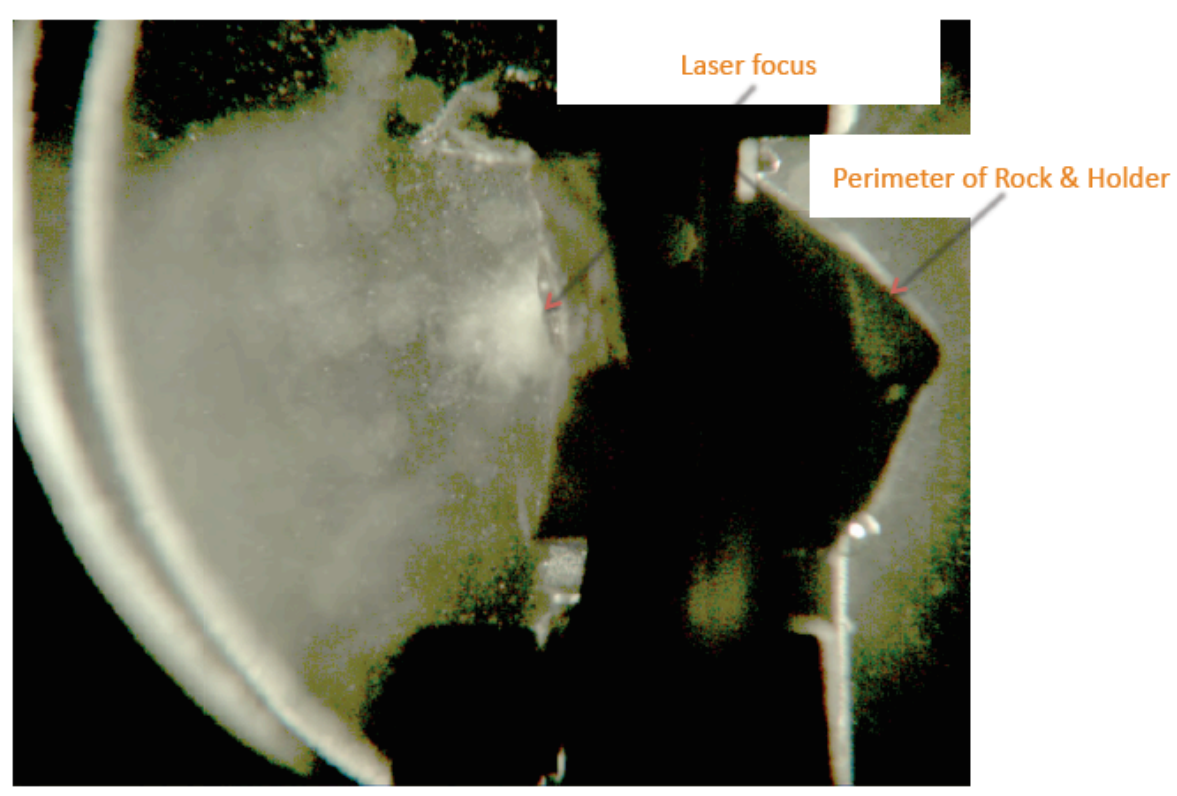

Figure 7. high-speed camera image of large particles generated by laser ablation of sample \#1, first series, seen through $2.5^{\prime \prime}$ viewport. 


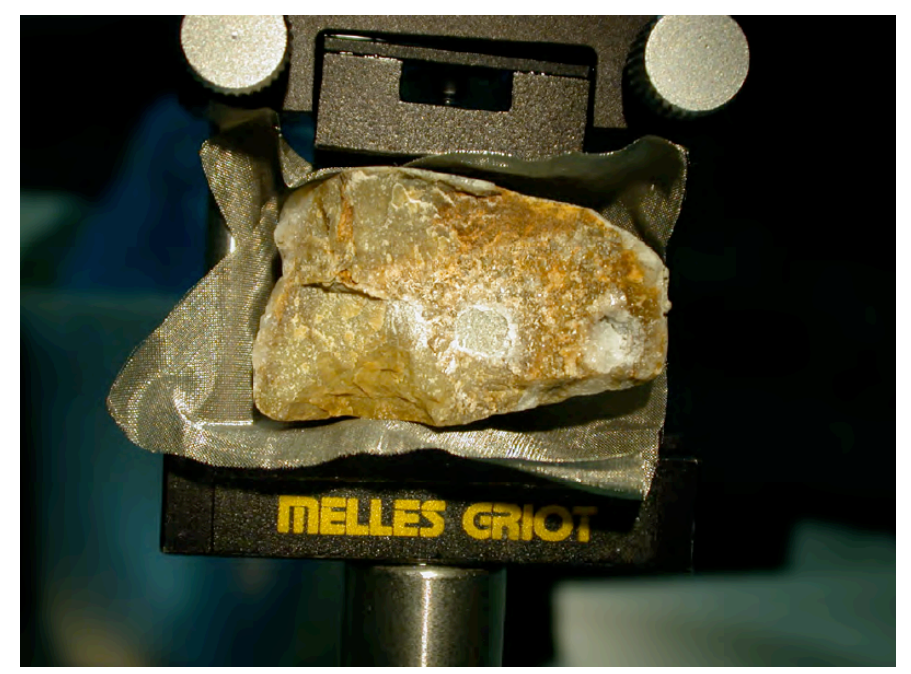

Figure 8. Photo of Sample\#1, after 0.7-J pulses, showing sample mounted in holder with 300mesh SS screen from The Western Group, 1 Blue Sky Ct., Sacramento, CA 95828

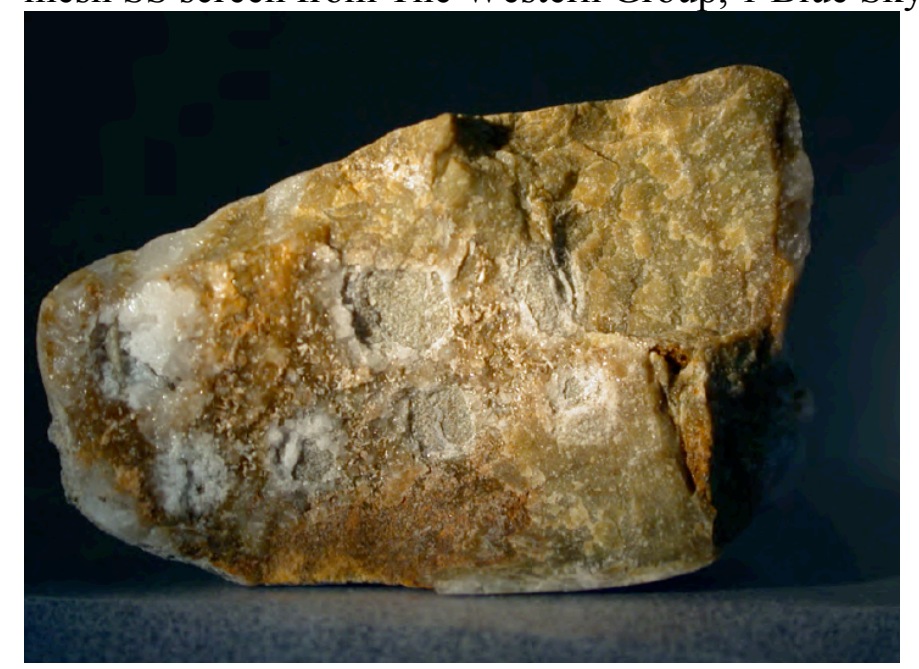

Figure 9. Photo of Sample\#1, after series of 0.7-J and 0.35-J pulses, upper and lower patterns, respectively

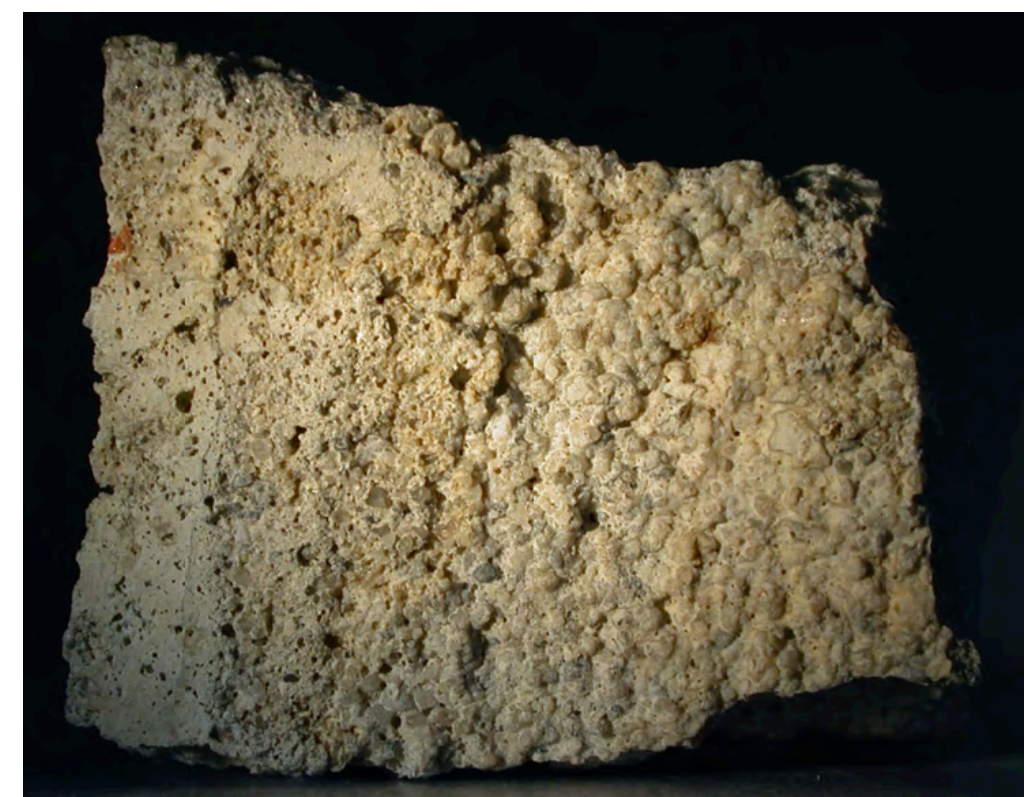

Figure 10. Pre-shot photo of sample \#2, concrete [9.751g, $2.0 \mathrm{~g} / \mathrm{cc}$ ] 


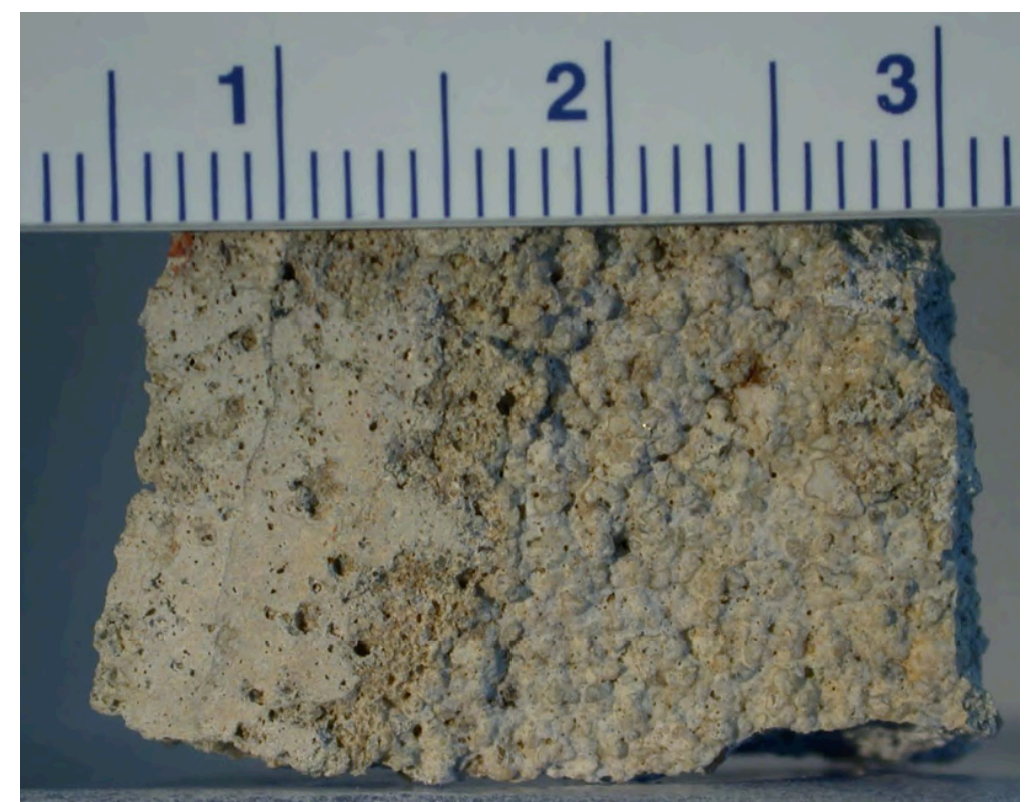

Figure 11. Pre-shot photo of sample \#2, with ruler

$1 \mathrm{~J}, 2.5-\mathrm{cm} 2351-\mathrm{nm}, 15-\mathrm{ns}$ pulses - UV laser pulses produced a suspension of microparticles in water via a controlled process of ablation into a plasma followed by condensation into the water

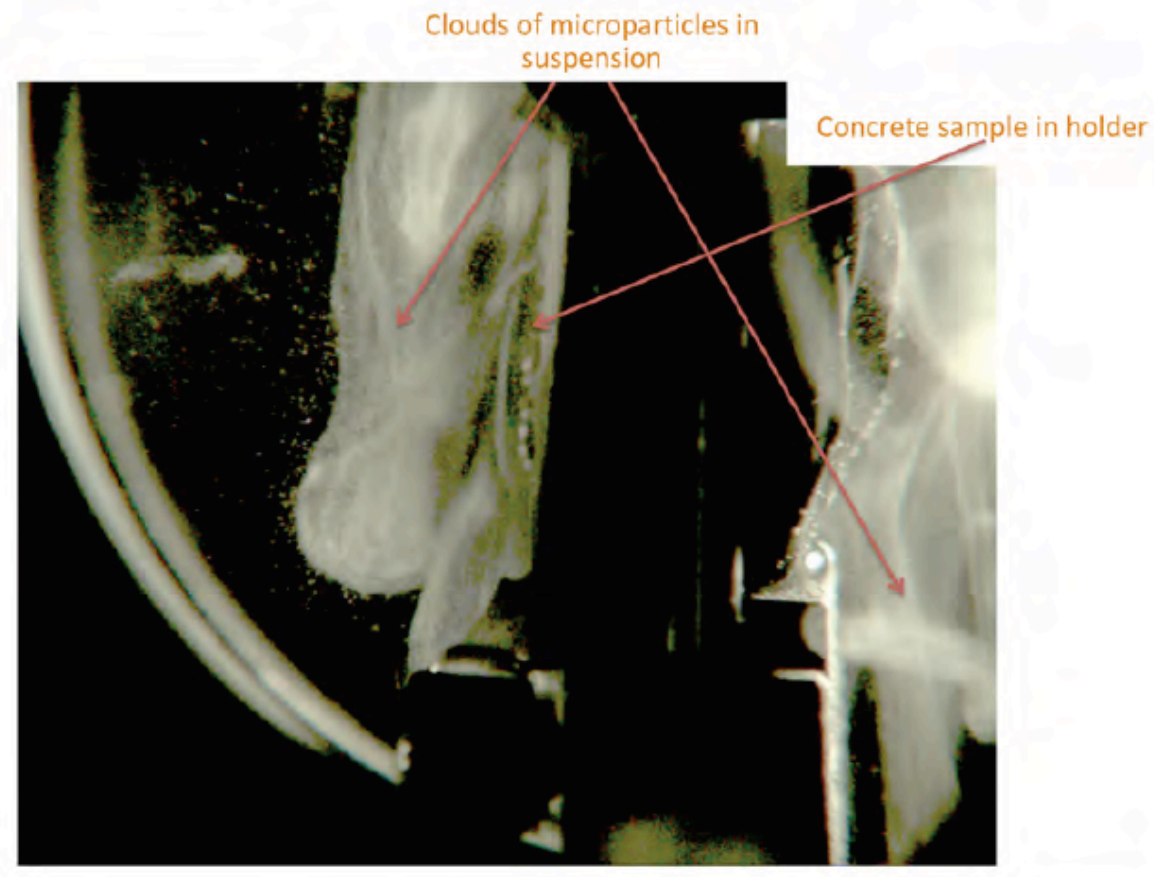

Figure 12. Photo of DI-water-filled chamber, with suspended particles from the ablation of sample \#2 with 100 one-joule pulses, $2.5-\mathrm{cm}^{2}$ area, 15-ns, at $351 \mathrm{~nm}$ - copious microparticles were produced and remained in suspension.

Figure 13 is a histogram of number of suspended particles $/ \mathrm{mL}$ versus particle size in $\mu \mathrm{m}$, from our experiments with sample \#1 and sample \#2. The indigo-blue color lines are from the water that immersed the rock in our first series of experiments that used $2000.7-\mathrm{J}$ pulses and 2000.35 $\mathrm{J}$ pulses, focused onto $\approx 0.1 \mathrm{~cm}^{2}$ area. The olive green-pink lines are from the water that 
immersed the piece of concrete, exposed to $1001-\mathrm{J}$ pulses on $\approx 2.5 \mathrm{~cm}^{2}$ area. Note the similarity in both distributions of particles.

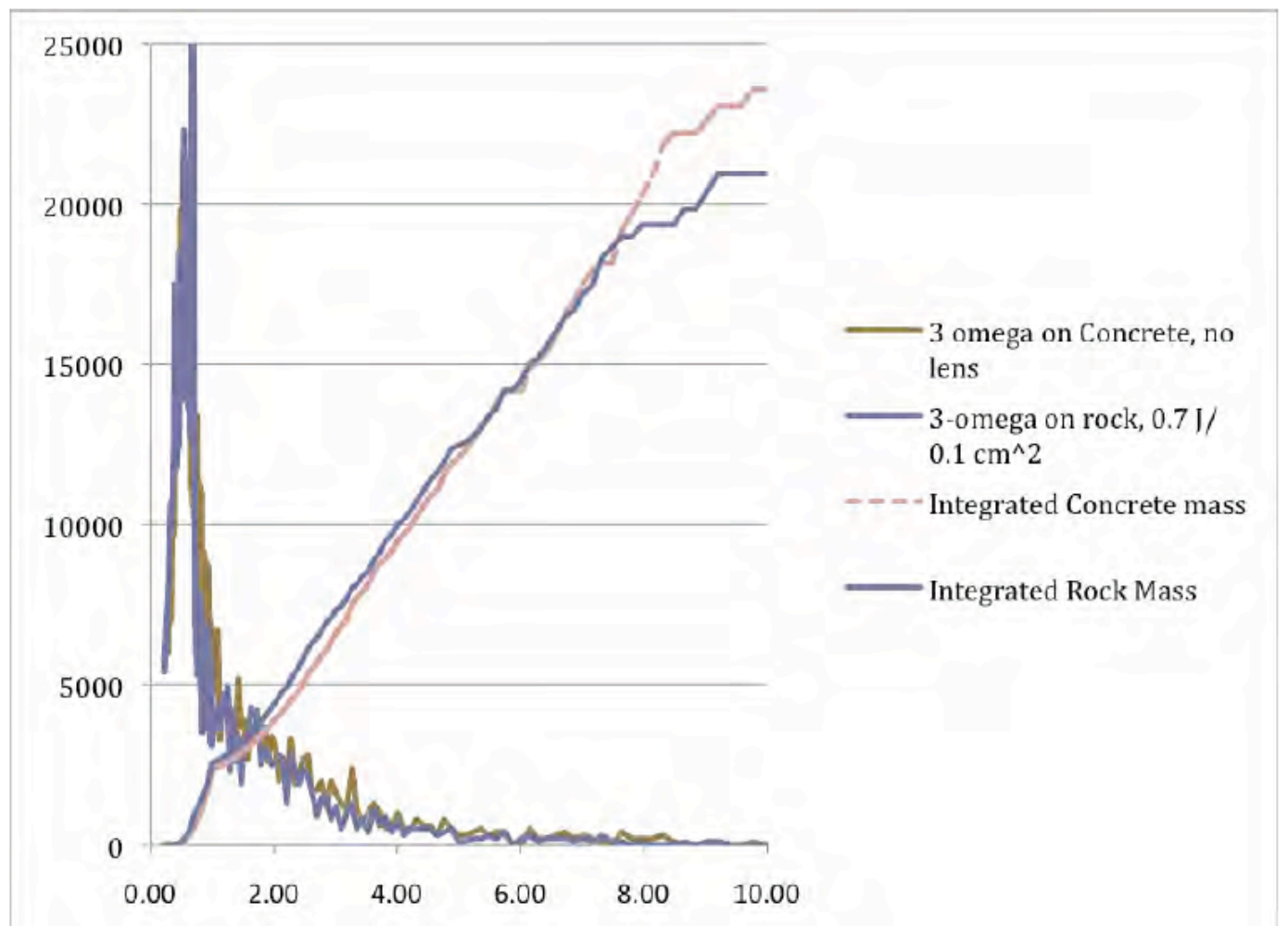

Figure 13. Histogram of particles generated by laser ablation versus particle diameter in $\mu \mathrm{m}$. Y axis is number of particles/size-bin $/ \mathrm{ml}$ of water. $\mathrm{X}$ axis is particle diameter in $\mu \mathrm{m}$. Data are for quartzite sample and concrete sample. Each sample had been immersed in $700 \mathrm{ml}$ of DI water. 


\section{References}

1. Ballard, P., Fournier, J., Fabbro, R., Frelat, J. \& Castex, L. STUDY OF THE PLASTIFICATION OF METALLIC TARGETS SHOCKED BY A LASER-PULSE OF HIGH-ENERGY. Journal De Physique 49, 401-406 (1988).

2. Cheng, W., Finnie, I., Gremaud, M., Rosselet, A. \& Streit, R.D. The compliance method for measurement of near surface residual stresses - application and validation for surface treatment by laser and shot-peening. Journal of Engineering Materials and Technology v116, p556(555) (1994).

3. Dane, C.B., Hackel, L.A., Daly, J. \& Harrison, J. Shot peening with lasers. Advanced Materials \&amp; Processes v153, p37(32) (1998).

4. Fabbro, R., Fournier, J., Ballard, P., Devaux, D. \& Virmont, J. PHYSICAL STUDY OF LASER-PRODUCED PLASMA IN CONFINED GEOMETRY. Journal of Applied Physics 68, 775-784 (1990).

5. Peyre, P., Fabbro, R., Berthe, L. \& Dubouchet, C. Laser shock processing of materials, physical processes involved and examples of applications. J. Laser Appl. 8, 135-141 (1996).

6. Clauer, A.H. Laser Shock Peening for Fatigue Resistance. Surface Performance of Titanium Eylon, D; Rack, HJ; Gregory, JK, 217 - 230 (1996).

7. White, R.M. Elastic Wave Generation by Electron Bombardment or Electromagnetic Wave Absorption. Journal of Applied Physics 34, 2123-\& (1963).

8. Anderholm, N.C. \& Boade, R.R. Laser-induced stress waves in quartz phenolic [Gruneisen parameter]. Journal of Applied Physics, 434-436 (1972).

9. Fox, J.A. Effect of water and paint coatings on laser-irradiated targets. Applied Physics Letters 24, 461-464 (1974).

10. Peyre, P., Chaieb, I. \& Braham, C. FEM calculation of residual stresses induced by laser shock processing in stainless steels. Modelling and Simulation in Materials Science and Engineering 15, 205 (2007).

11. Tam, A.C., Park, H.K. \& Grigoropoulos, C.P. Laser cleaning of surface contaminants. Applied Surface Science 127-129, 721-725 (1998).

12. Berthe, L., Fabbro, R., Peyre, P., Tollier, L. \& Bartnicki, E. Shock waves from a waterconfined laser-generated plasma. Journal of Applied Physics 82, 2826-2832 (1997).

13. Sano, Y., Mukai, N., Okazaki, K. \& Obata, M. Residual stress improvement in metal surface by underwater laser irradiation. Nuclear Instruments and Methods in Physics Research Section B: Beam Interactions with Materials and Atoms 121, 432-436 (1997).

14. Peyre, P., Fabbro, R., Merrien, P. \& Lieurade, H.P. Laser shock processing of aluminium alloys. Application to high cycle fatigue behaviour. Materials Science and Engineering $A$ 210, 102-113 (1996).

15. Glemser, O., Stocker, U. \& Wendland.Hg. ZUR REAKTION VON FESTEN OXIDEN MIT HOCHVERDICHTETEM WASSER BEI HOHEREN TEMPERATUREN. Berichte Der Bunsen-Gesellschaft Fur Physikalische Chemie 70, 1129-\& (1966).

16. Matson, D.W. \& Smith, R.D. SUPERCRITICAL FLUID TECHNOLOGIES FOR CERAMIC-PROCESSING APPLICATIONS. J. Am. Ceram. Soc. 72, 871-881 (1989).

17. von Gutfeld, R.J. \& Hodgson, R.T. Laser enhanced etching in KOH. Applied Physics Letters 40, 352-354 (1982).

18. Sajti, C.L., Sattari, R., Chichkov, B.N. \& Barcikowski, S. Gram Scale Synthesis of Pure Ceramic Nanoparticles by Laser Ablation in Liquid. The Journal of Physical Chemistry C 114, 2421-2427 (2010). 
19. Musaev, O.R., Midgley, A.E., Wrobel, J.M. \& Kruger, M.B. Laser ablation of alumina in water. Chemical Physics Letters 487, 81-83 (2010).

20. Barcikowski, S., Hahn, A., Kabashin, A.V. \& Chichkov, B.N. Properties of nanoparticles generated during femtosecond laser machining in air and water. Applied Physics A: Materials Science \& Processing 87, 47-55 (2007).

21. Mhin, S., et al. Simple synthetic route for hydroxyapatite colloidal nanoparticles via a Nd:YAG laser ablation in liquid medium. Applied Physics A: Materials Science \& Processing 96, 435-440 (2009).

22. Semaltianos, N., et al. II-VI semiconductor nanoparticles synthesized by laser ablation. Applied Physics A: Materials Science \& Processing 94, 641-647 (2009).

23. Geiger, M., Becker, W., Rebhan, T., Hutfless, J. \& Lutz, N. Increase of efficiency for the $\mathrm{XeCl}$ excimer laser ablation of ceramics. Applied Surface Science 96-8, 309-315 (1996).

24. Zhu, S., Lu, Y.F. \& Hong, M.H. Laser ablation of solid substrates in a water-confined environment. Applied Physics Letters 79, 1396-1398 (2001).

25. Rubenchik, A.M., Feit, M.D., Perry, M.D. \& Larsen, J.T. Numerical simulation of ultrashort laser pulse energy deposition and bulk transport for material processing. Applied Surface Science 127, 193-198 (1998).

26. Berthe, L., Fabbro, R., Peyre, P. \& Bartnicki, E. Wavelength dependent of laser shockwave generation in the water-confinement regime. Journal of Applied Physics 85, 75527555 (1999).

27. Glenzer, S.H., et al. Thomson scattering from inertial-confinement-fusion Hohlraum plasmas. Physical Review Letters 79, 1277-1280 (1997).

28. Gregori, G., et al. Effect of Nonlocal Transport on Heat-Wave Propagation. Physical Review Letters 92, 205006 (2004).

29. Glenzer, S.H. \& Redmer, R. X-ray Thomson scattering in high energy density plasmas. Reviews of Modern Physics 81, 1625 (2009).

30. Rubenchik, A.M. Simple model for laser ablation of a solid, submerged in water. private communication (2009).

31. Peyre, P. \& Fabbro, R. Laser shock processing: A review of the physics and applications. Opt. Quantum Electron. 27, 1213-1229 (1995).

32. Stanford P. Lyon, J.D.J., Group T-1 Editors. SESAME: THE LOS ALAMOS NATIONAL LABORATORY EQUATION OF STATE DATABASE. Los Alamos Technical Report LA-UR-92-3407.

33. Sollier, A., et al. A new experimental design for laser-driven shocks on precompressed and preheated water samples. in Shock Compression of Condensed Matter - 2007, Pts 1 and 2, Vol. 955 (eds. Elert, M., Furnish, M.D., Chau, R., Holmes, N.C. \& Nguyen, J.) 1192-1195 (Amer Inst Physics, Melville, 2007).

34. Kibble, T.W.B. TOPOLOGY OF COSMIC DOMAINS AND STRINGS. Journal of Physics a-Mathematical and General 9, 1387-1398 (1976).

35. Martins, C. \& Shellard, E.P.S. Evolution of superconducting strings. Astrophys. Space Sci. 261, 321-322 (1998).

36. Berthe, L., Sollier, A., Peyre, P., Fabbro, R. \& Bartnicki, E. The generation of laser shock waves in a water-confinement regime with $50 \mathrm{~ns}$ and $150 \mathrm{~ns} \mathrm{XeCl}$ excimer laser pulses. $J$. Phys. D-Appl. Phys. 33, 2142-2145 (2000).

37. Sollier, A., Berthe, L. \& Fabbro, R. Numerical modeling of the transmission of breakdown plasma generated in water during laser shock processing. Eur. Phys. J.-Appl. Phys 16, 131-139 (2001).

38. Stokes, G.G. On the effect of the internal friction of fluids on the motion of pendulums. Trans. Cambridge Philos. Soc. 9, 8 - 106 (1851).

39. van Dyke, M. Nineteenth-Century Roots Of The Boundary-Layer Idea*. Society for Industrial and Applied Mathematics Review 36, 415 - 424 (1994). 
40. Hill, M.R., et al. Laser peening technology. Adv. Mater. Process. 161, 65-67 (2003).

41. Jackson, K. private communication (2010).

42. Bacri, J. \& Raffanel, S. Calculation of Some Thermodynamic Properties of Air Plasmas Internal Partition-Functions, Plasma Composition, and Thermodynamic Functions. Plasma Chemistry and Plasma Processing 7, 53-87 (1987). 


\section{Lamé Constants}

The constants $\lambda$ and $\mu$ arising in strain-stress relationships. They are given in terms of other solid properties as

$$
\begin{aligned}
\lambda & \equiv \frac{\nu E}{(1+\nu)(1-2 \nu)} \\
& =K-\frac{2}{3} G \\
& =\frac{2 \nu G}{1-2 \nu} \\
& =3 K \frac{\nu}{1+\nu} \\
& =\rho\left(v_{p}^{2}-2 v_{s}^{2}\right) \\
& \equiv \frac{E}{2(1+\nu)} \\
& =\frac{3}{2}(K-\lambda) \\
& =\lambda \frac{1-2 \nu}{2 \nu} \\
& =3 K \frac{1-2 \nu}{2+2 \nu} \\
& =\rho v_{s}^{2},
\end{aligned}
$$

where $E$ is Young's modulus, $\nu$ is the Poisson ratio, $G$ is the shear modulus, $K$ is the bulk modulus, $\rho$ is the density, $v_{p}$ is $P$-wave speed, and $v_{s}$ is the S-wave speed. 
LLNL-TR-XYXYXY 